\title{
Avaliação da economia de água potável com a implantação de um sistema de aproveitamento de água de chuva: estudo de caso no município de Irati, Paraná
}

\author{
Evaluation of the economics of drinking water with the establishment of \\ a rainwater system: case study in Irati, Paraná
}

\author{
Adelena Gonçalves Maial(*) \\ Alison Luiz dos Santos ${ }^{2}$ \\ Paulo Costa de Oliveira Filho ${ }^{3}$
}

\section{Resumo}

O uso de sistemas de aproveitamento de água de chuva tem aumentado em todo o mundo, para minimizar a escassez hídrica local ou como uma fonte alternativa que viabilize a economia de água potável. O presente trabalho estuda o potencial de economia de água potável com a implantação de sistemas de aproveitamento de água de chuva em residências do município de Irati, Paraná. Os dados de área de telhado residencial foram levantados a partir de imagens satelitárias de alta resolução da área de estudo e foram utilizadas duas metodologias no dimensionamento dos reservatórios, que consideram respectivamente o aumento percentual de economia de água potável e a confiabilidade do sistema. Os reservatórios foram dimensionados considerando diferentes faixas de área de captação, para as quais foram calculadas a economia de água que o sistema proporcionaria. A economia média de água potável, com a implantação do sistema, foi de 44,92\%, que representa um valor diário de $148,43 \mathrm{~m}^{3}$.

Palavras-chave: água de chuva; sensoriamento remoto de alta resolução; dimensionamento de reservatório.

\section{Abstract}

The use of rainwater systems has increased worldwide, to minimize the local water scarcity or as an alternative source that makes possible the saving of drinking water.

I Dra.; Engenheira Civil; Professora do Departamento de Engenharia Civil da Universidade Federal do Rio Grande do Norte, UFRN; Endereço: Caixa Postal: I524, Campus Universitário Lagoa Nova, CEP: 59.072970, Natal, Rio Grande do Norte, Brasil; E-mail: adelena@ct.ufrn.br (*) Autora para correspondência.

2 Engenheiro Ambiental; Especializando em Georreferenciamento de Imóveis Rurais na Universidade Federal do Paraná, UFPR; E-mail: alison_san@hotmail.com

3 Dr.; Engenheiro Florestal; Professor do Departamento de Engenharia Ambiental da Universidade Estadual do Centro-Oeste, UNICENTRO; E-mail: paulocostafh@irati.unicentro.br

Recebido para publicação em 0I/II/2010 e aceito em I I/04/201 I

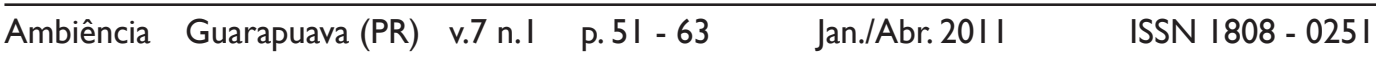

DOI: $10.5777 /$ ambiencia.2011.01.05 
This paper studies the potential savings of potable water with the implantation of rainwater systems in Brazilian residences in Irati, Paraná. Data on residential roof area were gathered from a satellite image of study area and two methods were used to choose the reservoir size, which consider the percentage increase in saving drinking water and system reliability. The reservoirs were designed considering different roof area ranges, from which one were calculated the water savings that the system would provide. The average savings for potable water, with the implementation of the system, was $44.92 \%$, representing a value of $148.43 \mathrm{~m} 3$ per day per household.

Key words: rain water; remote sensing; high-resolution sizing of the reservoir.

\section{Introdução}

Os sistemas de aproveitamento de água de chuva têm tido uma crescente aplicação nas áreas urbanas: estes sistemas atuam como fonte alternativa de abastecimento de água e minimizam os problemas relacionados à indisponibilidade hídrica para o atendimento das crescentes demandas. Gomes et al. (2010) salientam que, embora o Brasil possa ser considerado privilegiado em termos de recursos hídricos, já enfrenta problemas relacionados à escassez de água, devidos a dois fatores principais: a distribuição espacial não uniforme e a degradação ambiental dos recursos hídricos.

$\mathrm{O}$ uso das águas pluviais no meio urbano viabiliza a economia da água tratada proveniente do sistema convencional de abastecimento de água, visto que uma parcela da demanda de água doméstica, comercial, pública, ou mesmo de uso industrial, pode ser suprida pelo sistema alternativo de captação e aproveitamento das águas pluviais.

Vários trabalhos desenvolvidos estimam a economia de água potável que um sistema de aproveitamento de água de chuva pode promover. Uma estimativa realizada por Ghisi (2006) teve como resultado uma economia de $48 \%$ a $100 \%$ da água potável, a depender da região geográfica brasileira analisada. Para a região Sul do
Brasil, por exemplo, a economia foi de $82 \%$. $\mathrm{O}$ autor ainda salienta que, em regiões onde a economia de água é superior a $50 \%$, é indicado o uso desta água também para fins potáveis, após tratamento adequado.

Ghisi et al. (2006) também realizaram uma pesquisa sobre a economia de água potável, em função do uso da água de chuva, por meio do levantamento dos dados de 62 cidades catarinenses, e obtiveram como resultado uma economia média de $69 \%$.

Marinoski e Ghisi (2008) encontraram um resultado de $48 \%$ de economia de água potável com a implantação de um sistema de aproveitamento de água de chuva no Centro de Tecnologia e Automação e Informática do SENAI de Santa Catarina.

Kuritza (2009) apresentou os resultados de um estudo sobre a economia de água potável, com o aproveitamento de água de chuva no município de União da Vitória (PR), onde encontrou uma resultado de economia de $24 \%$ de água potável, com o uso de reservatório de $1 \mathrm{~m}^{3}$, e uma economia de $44 \%$, com o uso de reservatório de $30 \mathrm{~m}^{3}$. Neste estudo, foi considerada uma demanda de água não potável de $50 \%$ da demanda total de água residencial.

De acordo com a ABNT (2007), o uso da água captada deve ser feito somente para fins não potáveis e, a depender do 
tratamento, estes usos podem ser: descargas em bacias sanitárias, irrigação de gramados e plantas ornamentais, lavagem de veículos, limpeza de calçadas e ruas, limpeza de pátios, espelhos d'água e usos industriais. Segundo Tomaz (2003), os usos não potáveis de água para rega de jardins, lavagens de automóveis e descargas em bacias sanitárias somam em torno de $50 \%$ da demanda total de água em uma residência.

De acordo com Tomaz (2001), as águas pluviais não devem ser utilizadas para uso potável.Já para Group Raindrops (2002), esta utilização é viável desde que sejam seguidas todas as recomendações de limpeza em conjunto com técnicas específicas de purificação.

Para dimensionar a capacidade de aproveitamento de água de chuva residencial é necessário determinar a área de superfície dos telhados residenciais, pois o dimensionamento dos reservatórios depende desta área de captação. Nos últimos anos, os avanços no campo do sensoriamento remoto, com o uso de imagens orbitais de alta resolução, têm proporcionado a obtenção de informações bastante detalhadas de estruturas urbanas e periurbanas, sendo possível o levantamento desses dados de forma mais precisa.

Conforme Vaeza et al. (2010), as técnicas de sensoriamento remoto e de geoprocessamento tornaram-se ferramentas úteis e indispensáveis no monitoramento da dinâmica de uso e ocupação da terra, pelo fato de propiciar maior frequência na atualização de dados, agilidade no processamento e viabilidade econômica.

O principal objetivo deste trabalho é analisar a potencialidade de aproveitamento de água de chuva na região urbana do município de Irati, para a determinação da possível economia de água do sistema convencional de abastecimento.

\section{Materiais e Métodos}

No presente trabalho foram realizadas simulações para a determinação da economia de água potável proporcionada por um sistema residencial de aproveitamento de água de chuva, a partir de diferentes áreas de captação de água de chuva. Para tanto, foram levantadas as áreas dos telhados na área de estudo a partir de sensoriamento remoto e dimensionado o tamanho do reservatório indicado para cada área de telhado.

\section{Área de Estudo}

O município de Irati localiza-se na macro-região sul e meso-região sudeste paranaense. Com a população estimada em 2009 de 58.136 habitantes, sendo 45.299 residente na área urbana e 12.837 na área rural. A cidade de Irati localiza-se no paralalelo 25 o 27' 56" de latitude Sul com interseção com o meridiano $50^{\circ} 37^{\prime} 51^{\prime \prime}$ de longitude Oeste (IRATI, 2010). A área de estudo restringiu-se aos seguintes bairros: D.E.R., Colina Nossa Senhora das Graças, Vila Nova, Canesianas e Alto da Glória (Figura 1).

\section{Levantamento da área de telhado}

Nesta etapa do trabalho foram utilizadas ortoimagens dos modos PAN e MS do sensor Quickbird-2 fusionadas com resolução espacial de 60 centímetros, da área urbana do Município de Irati de novembro de 2008, cedidas pela Prefeitura Municipal de Irati. Para este trabalho, foram utilizados os seguintes aplicativos: Sistema de Processamento de Informações Georreferenciadas - SPRING versão 5.1.5 do Instituto Nacional de Pesquisas Espaciais 


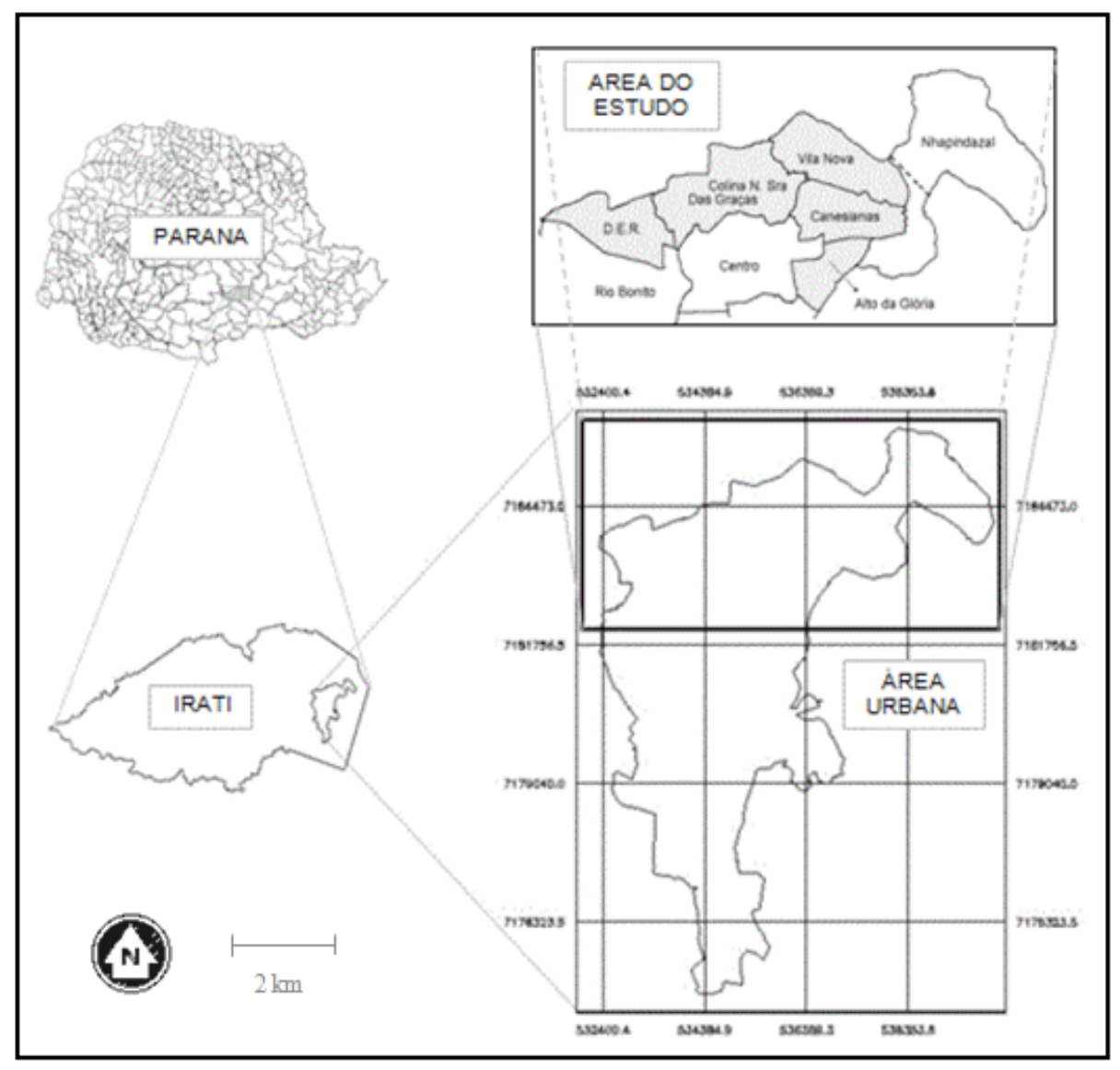

Figura I. Área do estudo correspondente a 5 bairros residenciais

- INPE@ e o sistema Excel da Microsoft ${ }^{\circledR}$ (Copyright-Microsoft Corporation).

A partir das imagens orbitais de alta resolução, foi realizada uma classificação orientada ao elemento da composição urbana "telhado", com o objetivo de levantar a área de telhados de unidades habitacionais da área de estudo, representando toda a variedade de padrões caracterizada pelas diferenças sócioeconômicas da população.

A área de telhado foi classificada através do processo de vetorização sobre tela, processo de classificação por interpretação, bastante utilizado em imagens de alta resolução. Para a determinação da classe específica de telhados residenciais, da área total e do número de residências identificadas, foi necessário selecionar alguns bairros em que o padrão observado de dimensão de telhados pudesse, tanto pelo arranjo espacial, pela organização de telhados, ou superfície, representar de uma forma geral o padrão médio das unidades habitacionais da cidade. As áreas acima de $200 \mathrm{~m}^{2}$ não foram consideradas como residenciais.

A partir da escolha dos bairros utilizados como área do estudo, realizou-se o recorte das imagens tendo como máscara de corte, os limites da área urbana utilizada no estudo. A seguir, iniciou-se o trabalho 
de interpretação e vetorização dos telhados. Após a vetorização, foi realizado o ajuste das linhas e poligonalização para satisfazer a condição topológica necessária para a obtenção das áreas dos telhados. A partir do módulo de verificação vetorial do sistema, foi possível selecionar e dimensionar os telhados por classes de área, considerando intervalos de classes de $10 \mathrm{~m}^{2}$.

\section{Dimensionamento dos reservató- rios}

Neste trabalho foram utilizadas duas metodologias associadas para o dimensionamento dos reservatórios, sendo elas:

1) Metodologia apresentada por Ghisi et al. (2007), na qual é simulada a operação do reservatório, considerando diferentes tamanhos de reservatórios e percentuais de atendimento da demanda residencial de água, para a determinação da economia de água potável do sistema. O reservatório escolhido é aquele capaz de proporcionar um aumento na economia, menor ou igual a $0,50 \%$, quando comparada com o percentual de economia do reservatório antecedente;

2) A segunda metodologia é a consideração da economia mínima de água potável de 90\%.

O tamanho do reservatório foi definido como o menor valor encontrado nas duas metodologias acima descritas.

\section{Simulações da operação do reservatório}

As simulações da operação dos reservatórios foram realizadas do equacionamento básico do balanço de massa do reservatório, a partir da equação 1 apresentada a seguir:
$S(t+1)=S(t)+V a(t)-D$

Onde: "S $(\mathrm{t}+1)$ "é o volume armazenado no início do intervalo " $t+1$ "; "S $(\mathrm{t})$ " é o volume de armazenamento no início do intervalo " $t$ "; "Va ( $t$ )" é o volume d'água precipitado aproveitável, durante o intervalo de tempo " $\mathrm{t}$ " e "D" é o volume efluente para o atendimento da demanda.

As simulações foram realizadas em intervalos diários de tempo e o fluxograma representativo do programa desenvolvido no Visual Basic aplicado aos objetos do Excel $^{\circledR}$ é apresentado na figura 2.

Os dados de entrada referentes à precipitação diária foram obtidos por meio da ANA (2008) e foram provenientes da Estação Climatológica Principal de Irati do Instituto Nacional de Meteorologia (INMET), localizada a uma latitude de $25^{\circ} 28^{\prime} 00^{\prime \prime} \mathrm{S}$ e $50^{\circ} 38^{\prime} 00^{\prime \prime} \mathrm{W}$ de longitude e uma altitude de $837 \mathrm{~m}$. A série histórica utilizada foi do período de outubro de 1966 a fevereiro de 2004.

As simulações foram realizadas para áreas de telhado com superfícies de 5 a 195 $\mathrm{m}^{2}$, considerando intervalos de $10 \mathrm{~m}^{2}$, entre as classes. Os tamanhos de reservatórios simulados foram de 1 a $30 \mathrm{~m}^{3}$, com variação de $1 \mathrm{~m}^{3}$.

Para a determinação da demanda média por residência, adotada nas simulações, foram necessárias informações referentes ao número de ligações do sistema e ao volume de água distribuído por mês pela companhia de abastecimento, dados estes obtidos junto à Companhia de Saneamento do Paraná (SANEPAR). Na tabela 1 também são apresentados os dados da população abastecida e demanda diária de água, sendo todos os dados referentes ao período de maio de 2009 a abril de 2010. 
Leia dados gerais do problema:

1. número de intervalo de tempo (tf);

2. precipitações $\left(\mathrm{P}_{\mathrm{t}}\right)$;

3. volume do reservatório $(\mathrm{Vr})$;

4. área de captação $(\mathrm{A})$;

5. coeficiente de escoamento superficial (c);

6. first-flush (FF);

7. demanda a ser atendida (D);

$$
\mathrm{t}=1
$$

Falhas $=0$

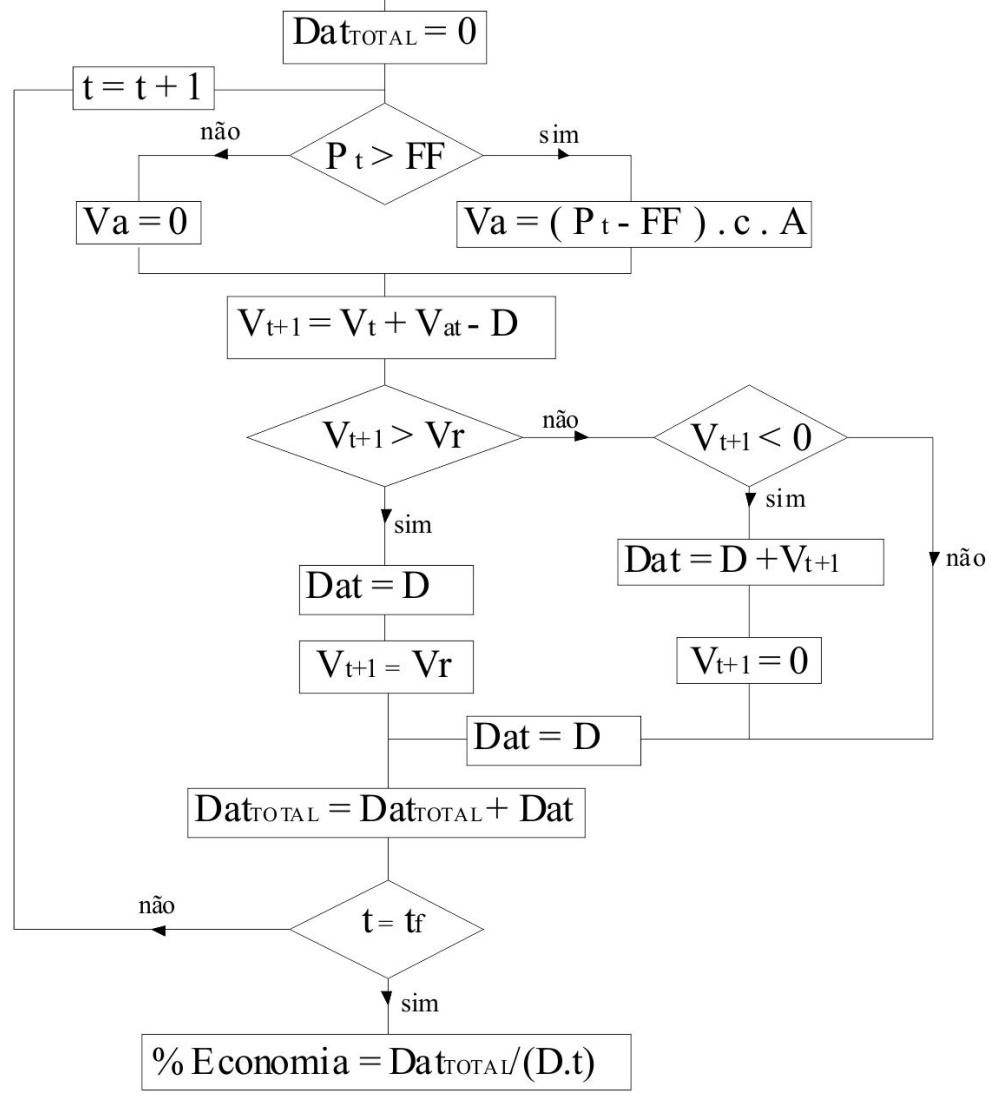

Figura 2. Fluxograma da simulação do reservatório 
Tabela I. Dados de demanda de água do Município de Irati, de 2009 a 2010

\begin{tabular}{ccccc}
\hline Mês & $\begin{array}{c}\text { População } \\
\text { Abastecida } \\
\text { (pessoas) }\end{array}$ & $\begin{array}{c}\text { Número de } \\
\text { Ligações }\end{array}$ & $\begin{array}{c}\text { Volume de Água } \\
\text { Distribuído } \\
\left(\mathrm{m}^{3} / \mathrm{mês}\right)\end{array}$ & $\begin{array}{c}\text { Demanda Diária } \\
\text { (L/Residência) }\end{array}$ \\
\hline MAI/09 & 41.095 & 12.174 & 121.745 & 333.35 \\
JUN/09 & 41.176 & 12.194 & 109.635 & 299.70 \\
JUL/09 & 41.257 & 12.211 & 108.888 & 297.24 \\
AGO/09 & 41.325 & 12.260 & 114.650 & 311.72 \\
SET/09 & 41.393 & 12.264 & 114.715 & 311.79 \\
OUT/09 & 41.461 & 12.286 & 118.487 & 321.47 \\
NOV/09 & 41.549 & 12.322 & 131.660 & 356.17 \\
DEZ/09 & 41.637 & 12.356 & 126.622 & 341.59 \\
JAN/10 & 41.722 & 12.391 & 141.053 & 379.45 \\
FEV/10 & 41.801 & 12.416 & 122.527 & 328.95 \\
MAR/10 & 41.879 & 12.419 & 123.334 & 331.04 \\
ABR/10 & 41.947 & 12.446 & 131.801 & 352.99 \\
\hline MÉDIA & 41.520 & 12.312 & 122.093 & 330.45 \\
\hline
\end{tabular}

Segundo Tomaz (2003), os usos não potáveis de água para rega de jardins, lavagens de automóveis e descargas em bacias sanitárias somam em torno de $50 \%$ da demanda total de água em uma residência. Portanto, para as simulações realizadas, foi considerado que a demanda de água nãopotável representa $50 \%$ da demanda de água total residencial, sendo assim, a demanda residencial diária utilizada foi de 165,23 litros.

O coeficiente de runoff, utilizado neste estudo, foi de 0,85 , para o cálculo do volume de água aproveitável de acordo com a equação 2 , apresentada a seguir.

$$
\mathrm{Va}=\mathrm{A} . c . P
$$

Onde: "Va" representa o volume de água precipitada aproveitável; "c" é o coeficiente de runoff, "P" a precipitação e "A" é a área de captação, projeção horizontal da área de telhado. Para o descarte inicial de cada chuva, conhecido como first-flush, foi adotado o valor de $1 \mathrm{~mm}$.

\section{Resultados e Discussão}

\section{Levantamento da área de telhado}

A figura 3 apresenta as áreas de telhado vetorizadas na região selecionada como área de estudo. Através da ferramenta de verificação de polígono do módulo de edição vetorial do aplicativo, foi realizada a seleção de todos os polígonos impondo a condição de área igual ou menor que $200 \mathrm{~m}^{2}$. Num total de 3.277 telhados analisados, foram encontrados 2.926 telhados com padrão habitacional, ou seja com área menor que $200 \mathrm{~m}^{2}$.

A seguir, o programa gerou um relatório (Figura 3) que foi exportado para o aplicativo Excel, onde foi realizada a distribuição de frequência de telhados por classes de área. As áreas de telhados foram distribuídas por frequência em classes de 10 em $10 \mathrm{~m}^{2}$ (Tabela 2) e foi gerado um gráfico da curva de permanência das classes de área de telhado (Figura 4). 
Tabela 2. Distribuição das classes de área de telhado

\begin{tabular}{|c|c|c|c|c|c|c|c|}
\hline $\begin{array}{l}\text { Classes de } \\
\text { Área de } \\
\text { Telhado } \\
\left(\mathrm{m}^{2}\right)\end{array}$ & $\begin{array}{l}\text { Área } \\
\text { Média } \\
\left(\mathrm{m}^{2}\right)\end{array}$ & $\begin{array}{l}\mathrm{N}^{0} \text { de } \\
\text { Res. por } \\
\text { Classe }\end{array}$ & $\begin{array}{l}\text { Ocorrência } \\
\text { da Classe } \\
(\%)\end{array}$ & $\begin{array}{l}\text { Classes de } \\
\text { rea de } \\
\text { felhado } \\
\left(\mathrm{m}^{2}\right)\end{array}$ & $\begin{array}{l}\text { Área } \\
\text { Média } \\
\left(\mathrm{m}^{2}\right)\end{array}$ & $\begin{array}{l}\mathrm{N}^{\circ} \text { de } \\
\text { Res. por } \\
\text { Classe }\end{array}$ & $\begin{array}{l}\text { Ocorrência } \\
\text { da Classe } \\
(\%)\end{array}$ \\
\hline $0-10$ & 5 & 11 & 0,38 & $100-110$ & 105 & 226 & 7,72 \\
\hline $10-20$ & 15 & 14 & 0,48 & $10-120$ & 125 & 221 & 7,55 \\
\hline $20-30$ & 25 & 52 & 1,78 & $20-130$ & 125 & 185 & 6,32 \\
\hline $30-40$ & 35 & 104 & 3,55 & $30-140$ & 135 & 142 & 4,85 \\
\hline $40-50$ & 45 & 187 & 6,39 & $40-150$ & 145 & 133 & 4,55 \\
\hline $50-60$ & 55 & 216 & 7,38 & $50-160$ & 155 & 130 & 4,44 \\
\hline $60-70$ & 65 & 222 & 7,59 & $60-170$ & 165 & 101 & 3,45 \\
\hline $70-80$ & 75 & 250 & 8,54 & $70-180$ & 175 & 86 & 2,94 \\
\hline $80-90$ & 85 & 271 & 9,26 & $80-190$ & 185 & 60 & 2,05 \\
\hline $90-100$ & 95 & 257 & 8,78 & $190-200$ & 195 & 58 & 2,00 \\
\hline \multicolumn{2}{|c|}{ SUB-TOTAIS } & 1.584 & 54,13 & & & 1.342 & 45,87 \\
\hline \multicolumn{2}{|l|}{ TOTAL } & & & & & 2.926 & 100,00 \\
\hline
\end{tabular}

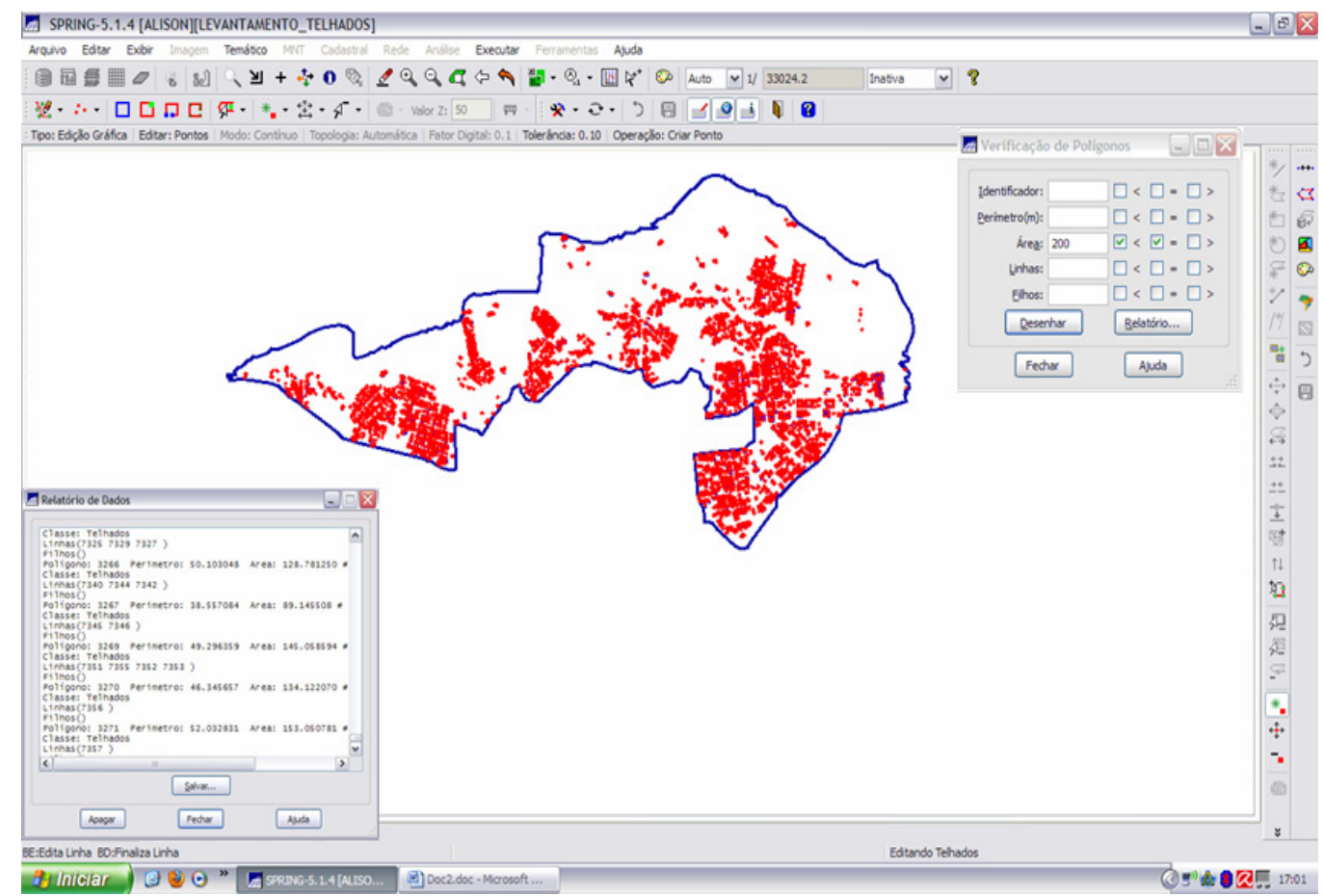

Figura 3. Tela do aplicativo SPRING evidenciando os polígonos representando telhados vetorizadas na região da área de estudo 


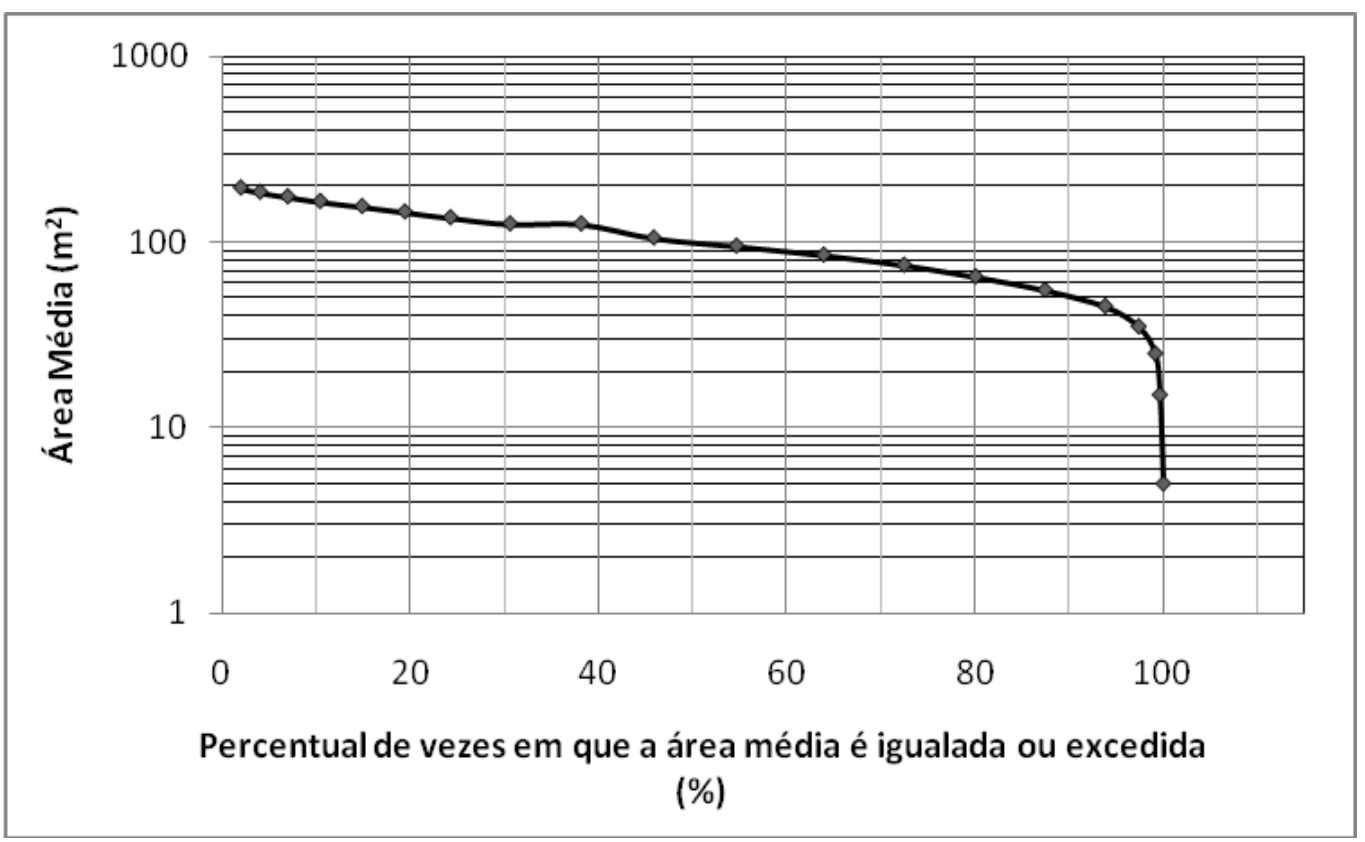

Figura 4. Curva de permanência das classes de área de telhado, com eixo da área de telhado logarítmico

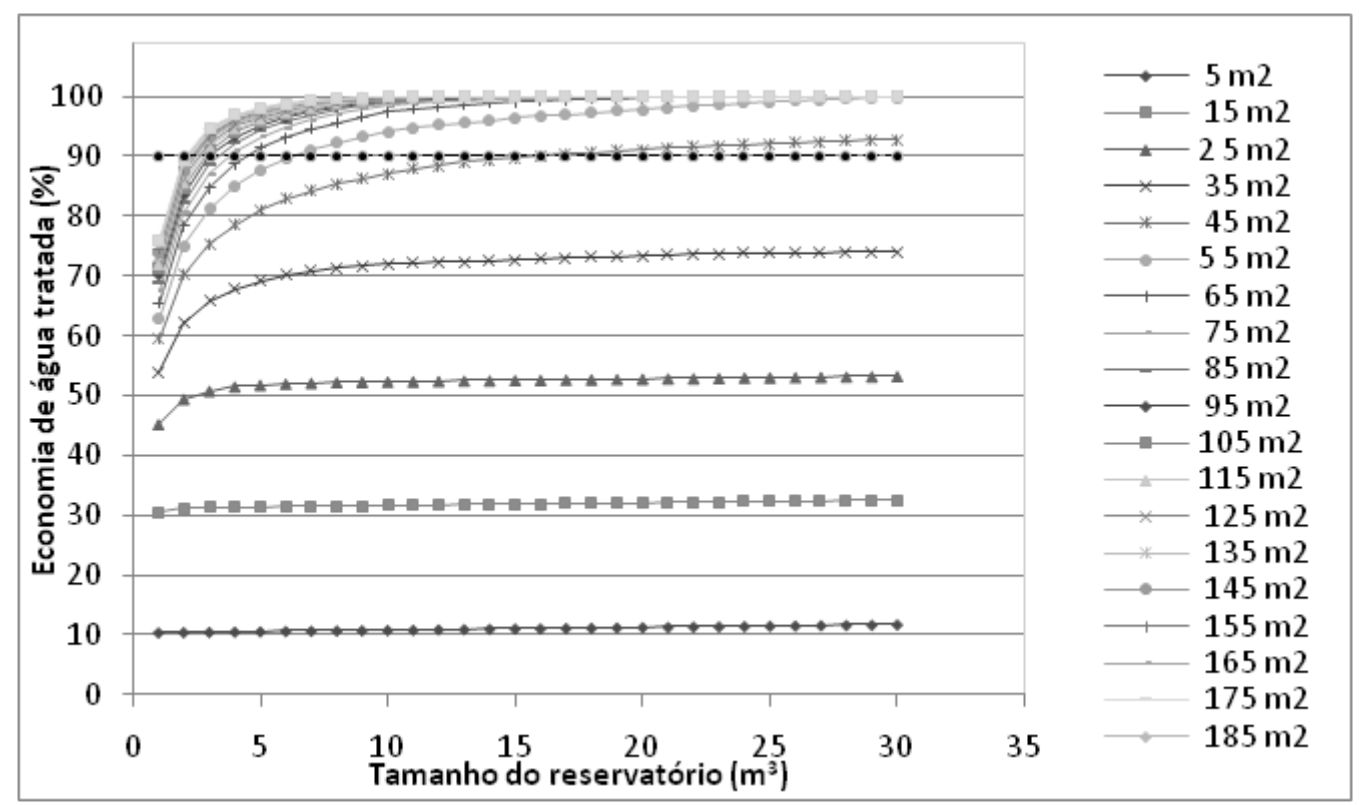

Figura 5. Potencial de economia de água tratada em função do tamanho do reservatório e da área de captação do telhado 


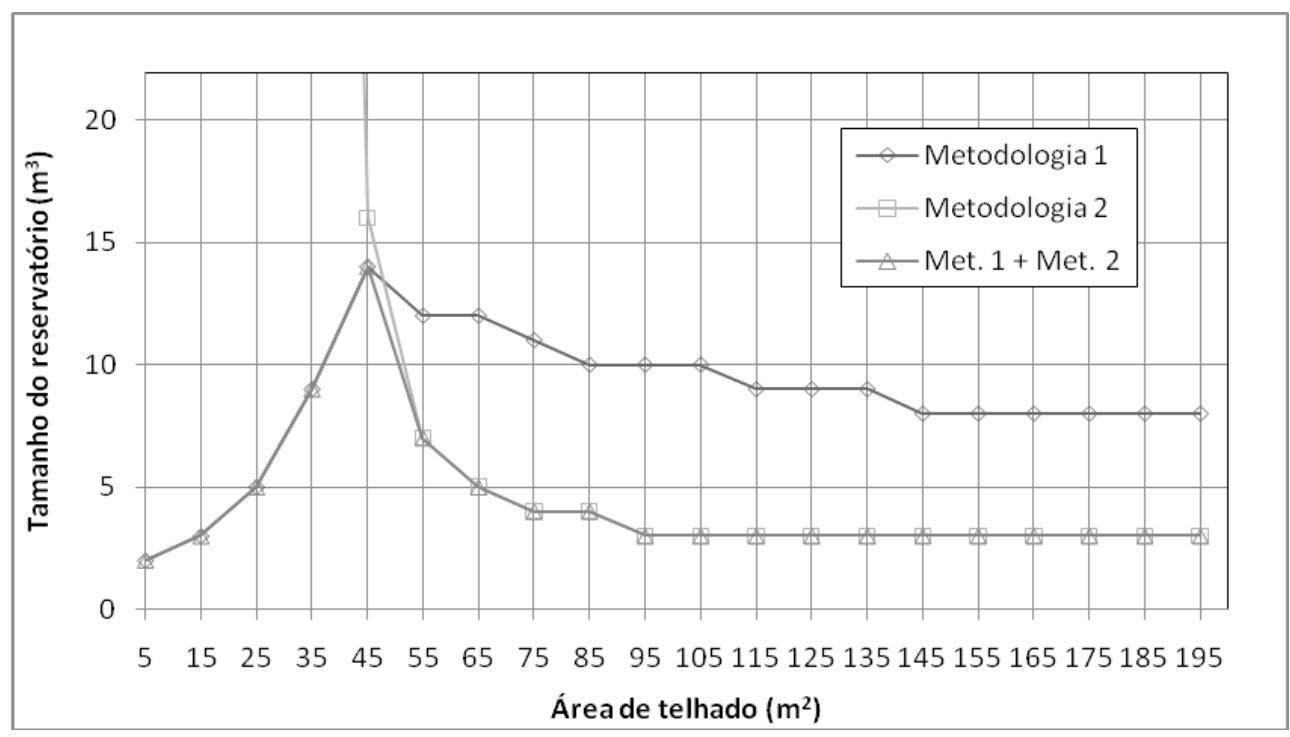

Figura 6. Dimensionamento de reservatório através das duas metodologias

Quadro I. Dimensionamento de reservatórios a partir das duas metodologias

\begin{tabular}{|l|l|l|l||l|l|l|l|}
\hline $\begin{array}{c}\text { Área } \\
\left(\mathrm{m}^{2}\right)\end{array}$ & $\begin{array}{c}\text { Reser. } \\
\text { Met. } \\
\left(\mathrm{m}^{3}\right)\end{array}$ & $\begin{array}{c}\text { Reser. } \\
- \text { Met. 2 } \\
\left(\mathrm{m}^{3}\right)\end{array}$ & $\begin{array}{c}\text { Reser. -Met. } \\
1+\text { Met. 2 } \\
\left(\mathrm{m}^{3}\right)\end{array}$ & $\begin{array}{c}\text { Área } \\
\left(\mathrm{m}^{2}\right)\end{array}$ & $\begin{array}{c}\text { Reser. - } \\
\text { Met. 1 } \\
\left(\mathrm{m}^{3}\right)\end{array}$ & $\begin{array}{c}\text { Reser. } \\
- \text { Met. 2 } \\
\left(\mathrm{m}^{3}\right)\end{array}$ & $\begin{array}{c}\text { Reser. -Met. } \\
1+\text { Met. 2 } \\
\left(\mathrm{m}^{3}\right)\end{array}$ \\
\hline 5 & 2 & - & 2 & 105 & 10 & 3 & 3 \\
\hline 15 & 3 & - & 3 & 125 & 9 & 3 & 3 \\
\hline 25 & 5 & - & 5 & 125 & 9 & 3 & 3 \\
\hline 35 & 9 & - & 9 & 135 & 9 & 3 & 3 \\
\hline 45 & 14 & 16 & 14 & 145 & 8 & 3 & 3 \\
\hline 55 & 12 & 7 & 7 & 155 & 8 & 3 & 3 \\
\hline 65 & 12 & 5 & 5 & 165 & 8 & 3 & 3 \\
\hline 75 & 11 & 4 & 4 & 175 & 8 & 3 & 3 \\
\hline 85 & 10 & 4 & 4 & 185 & 8 & 3 & 3 \\
\hline 95 & 10 & 3 & 3 & 195 & 8 & 3 & 3 \\
\hline
\end{tabular}

A figura 4 apresenta a curva de permanência das áreas médias de telhado, como o eixo das coordenadas em escala logarítmica, para maior ênfase das faixas de área de telhado mais baixas. Observa-se, na figura $4 \mathrm{e}$ na tabela 2 , que as concentrações de área de telhado só se tornam relevantes a partir da faixa de 40 a $50 \mathrm{~m}^{2}$; para áreas maiores que estas, as concentrações têm poucas variações, até a faixa de 120 a $130 \mathrm{~m}^{2}$, a partir de onde ocorre novamente a diminuição da ocorrência das classes.

\section{I Dimensionamento dos reservatórios}

As simulações da operação dos reservatórios foram realizadas para que fosse 
possível dimensionar os reservatórios. Os resultados destas simulações são apresentados na figura 5 .

Neste gráfico, observa-se a redução do ganho de economia de água tratada, para cada área de telhado, com o aumento do tamanho do reservatório e, justamente quando o aumento desta economia é inferior a $0,5 \%$ é que ocorre a definição do tamanho do reservatório "ideal", de acordo com a primeira metodologia proposta. Isso corre para áreas de telhado de até $45 \mathrm{~m}^{2}$. Para reservatórios maiores que $45 \mathrm{~m}^{2}$, foi imposta a segunda metodologia de dimensionamento na qual é definido um valor mínimo de economia de água tratada de $90 \%$. A figura 6 e o quadro 1 apresentam os resultados do dimensionamento do reservatório a partir das duas metodologias

Pela metodologia 1 existe um rápido crescimento do tamanho do reservatório dimensionado com o aumento da área de captação, chegando a reservatório de até 14 $\mathrm{m}^{3}$ para área de $45 \mathrm{~m}^{2}$; a partir da área de 45 $\mathrm{m}^{2}$, ocorre um decréscimo do tamanho do reservatório.
Pela metodologia 2 não foi possível realizar o dimensionamento de reservatórios para áreas de telhado de até $35 \mathrm{~m}^{2}$, visto que o percentual de $90 \%$ não foi atingido, ocorrendo, a partir deste valor, um decréscimo do tamanho do reservatório dimensionando, até se atingir o valor de $3 \mathrm{~m}^{3}$.

A associação das duas metodologias para o dimensionamento final do reservatório foi proposta para que não fossem considerados elevados valores de tamanho de reservatório, o que acarretaria um grande investimento inicial, para a instalação do sistema, e consequente aumento do tempo de retorno do investimento, o que poderia acarretar em sistemas pouco atraentes de serem implementados.

\section{Economia de água do sistema}

O quadro 2 apresenta os resultados da economia de água de cada área média de classe de área de telhado, considerando o tamanho de reservatório dimensionado e apresentado no quadro 1 e a economia de

Quadro 2. Economia média de cada classe de telhado considerando os diferentes tamanhos de reservatórios

\begin{tabular}{|l|l|l||l|l|l|}
\hline $\begin{array}{c}\text { Área de } \\
\text { telhado média } \\
\text { da classe } \\
\left(\mathrm{m}^{2}\right)\end{array}$ & $\begin{array}{c}\text { Ocorrência da } \\
\text { classe }(\%)\end{array}$ & $\begin{array}{c}\text { Economia } \\
\text { de água }(\%)\end{array}$ & $\begin{array}{c}\text { Área de telhado } \\
\text { média da classe } \\
\left(\mathrm{m}^{2}\right)\end{array}$ & $\begin{array}{c}\text { Ocorrência } \\
\text { da classe }(\%)\end{array}$ & $\begin{array}{c}\text { Economia } \\
\text { de água }(\%)\end{array}$ \\
\hline 5 & 0,38 & 10,48 & 105 & 7,72 & 90,95 \\
\hline 15 & 0,48 & 31,28 & 125 & 7,55 & 91,71 \\
\hline 25 & 1,78 & 51,81 & 125 & 6,32 & 92,33 \\
\hline 35 & 3,55 & 71,73 & 135 & 4,85 & 92,85 \\
\hline 45 & 6,39 & 90,12 & 145 & 4,55 & 93,29 \\
\hline 55 & 7,38 & 91,05 & 155 & 4,44 & 93,67 \\
\hline 65 & 7,59 & 91,40 & 165 & 3,45 & 94,00 \\
\hline 75 & 8,54 & 90,91 & 175 & 2,94 & 94,29 \\
\hline 85 & 9,26 & 92,33 & 185 & 2,05 & 94,54 \\
\hline 95 & 8,78 & 90,00 & 195 & 2,00 & 94,74 \\
\hline
\end{tabular}


água encontrada para o referido tamanho de reservatório e respectiva área de telhado (figura 5).

A partir destes dados, foi feita uma média ponderada da economia de água em função das ocorrências de cada classe, tendo como resultado uma economia média de $89,83 \%$, que representa um valor de 148,43 $\mathrm{m}^{3}$ diários, da demanda não potável de água de $165,23 \mathrm{~m}^{3} /$ dia. Este percentual representa uma economia de $44,92 \%$ da demanda total de água residencial.

\section{Conclusões}

O uso de imagem de satélite para o levantamento dos dados de tamanho de área de telhado proporciona a obtenção de resultados mais confiáveis do que o uso de taxas de área de telhado por habitantes da residência, metodologia esta que costuma ser utilizada para o levantamento desta informação.

Os reservatórios dimensionados pela metodologia 1, para área de captação de até $45 \mathrm{~m}^{2}$, apresentam baixa economia de água, devida à reduzida área de telhado, no entanto com o uso desta metodologia, buscou-se dimensionar o reservatório em função do seu potencial de economia, de modo que a relação custo-benefício do sistema fosse considerada. No entanto, os reservatórios a partir de 45 $\mathrm{m}^{2}$, dimensionados pela metodologia 2 , apresentam elevada economia de água, não tendo o seu dimensionamento nenhuma relação com o custo-benefício e sim com a eficiência do sistema.

A elevada taxa de economia de água não potável encontrada, de 89,83\% em média, é um indicativo do elevado potencial de economia que o sistema pode proporcionar se instalado em residências da área de estudo. No entanto, não se espera que haja uma adesão maciça ao sistema, mesmo assim elevadas taxas de economia podem ser conseguidas de forma individual, pelas residências com área de telhado superiores a $45 \mathrm{~m}^{2}$. Para os domicílios com área de telhado inferiores que $45 \mathrm{~m}^{2}$, o sistema pode ser considerado menos atrativo, devido às taxas de economia serem menos expressivas.

Apesar dos resultados apresentados de dimensionamento de reservatórios, o proprietário interessado no sistema pode se decidir por reservatórios com tamanhos diferentes dos sugeridos, em função dos resultados apresentados, neste trabalho, da economia que cada reservatório pode proporcionar e do capital inicial disponível para investimento no sistema.

\section{Agradecimentos}

Os autores agradecem à Universidade Estadual do Centro-Oeste, UNICENTRO, pela bolsa modalidade BIC - Bolsa de Iniciação Científica, à Prefeitura Municipal de Irati pela cessão das imagens de Satélite e à SANEPAR pelos dados de abastecimento de água disponibilizados.

\section{Referências}

ASSOCIAÇÃO BRASILEIRA DE NORMAS TÉCNICAS - ABNT. Aproveitamento de água de chuva para fins não potáveis em áreas urbanas. Diretrizes. Rio de Janeiro: 2007. 7p. 
AGÊNCIA NACIONAL DE ÁGUAS - ANA. HidroWeb: Sistemas de Informação Hidrológicas. Disponível em: <http://hidroweb.ana.gov.br/>. Acesso em: 7 ago. 2008.

GHISI, E. Potential for potable water saving by using rainwater in the residential sector of Brazil. Building and Environment, [S.I.], v. 41, p. 1544-1550, 2006.

GHISI, E.; BRESSAN, D. L.; MARTINI, M. Rainwater tank capacity and potential for potable water savings by using rainwater in the residential sector of southeastern Brazil. Building and Environment, v. 42, p.1654-1666, 2007.

GHISI, E.; MONTIBELLER, A.; SCHMIDT, R.W. Potential for potable water savings by using rainwater : an analysis over 62 cities in southern Brazil. Building and Environment, v. 41, p. 204-210, 2006.

GOMES, J.; WEBER, D. C.; DELONG, C. M. Dimensionamento de Reservatório de Armazenamento de Águas Pluviais, usando um Critério Financeiro. Revista Brasileira de Recursos Hídricos, Porto Alegre, v. 15, n.1, p 89-100, jan/mar 2010.

GROUP RAINDROPS. Manual de utilização das águas pluviais (100 maneiras práticas). Curitiba: Livraria Chain, 2002. 167p. Tradução de Roberto Fendrich e Rogério Oliynik. Tradução da versão inglesa de Nichibei Kaiwa Gakuin do original japonês "Yatte Miyo Amamizu Riyo".

IRATI. Localização Geográfica. 2010. Disponível em: <http://www.irati.pr.gov.br/ municipio/localizaçaogeografica.asp>. Acesso em: 22 mar. 2010.

KURITZA, J. C. Estudo do aproveitamento de água de chuva no município de União da Vitória (PR). [S.I]. Trabalho de Conclusão de Curso (Engenharia Ambiental) - Universidade Estadual do Centro-Oeste, UNICENTRO, Irati, 2009.

MARINOSKI, A. K.; GHISI, E. Aproveitamento de água pluvial para usos não potáveis em instituição de ensino: estudo de caso em Florianópolis-SC. Ambiente Construído, Porto Alegre, v. 8, n. 2, p. 67-84, 2008.

TOMAZ, P. Aproveitamento de Água de Chuva. Aproveitamento de Água de Chuva para Áreas Urbanas e Fins não Potáveis. Navegar. São Paulo, SP. 2003.

TOMAZ, P. Economia de água para empresas e residências: um estudo atualizado sobre o uso racional da água. São Paulo: Navegar, 2001.112 p.

VAEZA, R. F.; OLIVEIRA-FILHO, P. C.; MAIA, A. G., DISPERATI, A. A. Uso e Ocupação Detalhada da Terra em Bacia Hidrográfica Urbana a Partir de Imagens Orbitais de Alta Resolução. Revista Floresta e Ambiente, Rio de Janeiro, v. 17, p. 23-29, UFRRJ, 2010. 